\section{Association of Exposure to Particular Matter and Carotid Intima-Media Thickness: A Systematic Review and Meta-Analysis}

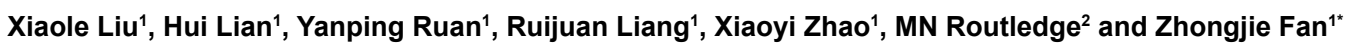

${ }^{1}$ Department of Cardiology, Peking Union Medical College Hospital, Peking Union Medical College and Chinese Academy of Medical Sciences, PR China ${ }^{2}$ Leeds Institute of Cardiovascular and Metabolic Medicine, University of Leeds, UK

\begin{abstract}
Long time exposure to particular matter has been linked to myocardial infarction, stroke and blood pressure, but its association with atherosclerosis is not clear. We did a systematic review and meta-analysis to assess whether particular matter has an effect on subclinical atherosclerosis measured by carotid intima-media thickness (CIMT).
\end{abstract}

Keywords: Air pollution; Particular matter; Carotid Intima-Media Thickness; Subclinical atherosclerosis; Meta-analysis

\section{Introduction}

The association between air pollution (especially particular matter) and cardiovascular disease (CVD) or their risk factors has been demonstrated by a great number of epidemiological and experimental studies [1-6]. Among the size fractions of particular matter, long term exposure to ambient and individual particular matter less than 2.5 $\mu \mathrm{m}$ in diameter $\left(\mathrm{PM}_{25}\right)$ is responsible for morbidity and mortality of cardiovascular events [7].

Atherosclerosis is a chronic process and mainly affects the aorta, coronary artery and cerebral artery, which often leads to serious consequences like lumen occlusion and plaque rupture. It is the major pathological process of heart disease and stroke. In western developed countries, atherosclerosis account for about $50 \%$ of all deaths [8-10]. Epidemiological studies have suggested that the degree of atherosclerosis can be measured by carotid intima-media thickness (CIMT) to forecast population's future cardiovascular risk [11-13]. Several studies of long term exposure to particular matter $\left(\mathrm{PM}_{2.5}, \mathrm{PM}_{10}\right)$ have shown that the higher particular matter concentrations were associated with increased CIMT. However, not all studies had found significant results, so the association between particular matter and CIMT is still uncertain. We therefore systematically reviewed the studies examining the effect of particular matter $\left(\mathrm{PM}_{2.5}, \mathrm{PM}_{10}\right)$ on CIMT and quantify this effect.

\section{Materials and Methods}

\section{Search strategy and eligibility criteria}

We performed a comprehensive databases search in PubMed, Ovid Medline, Embase and CNKI using the key words as follows: "air pollution", "air pollutants", "particular matter", " $\mathrm{PM}_{2.5}$ ", "PM 10 ", "meteorological factor", "carotid intima-media thickness", "Carotid atherosclerosis", "carotid IMT", "CIMT" and "subclinical atherosclerosis". The publication date of literatures was limited between 1948 and March 31, 2015. Literatures were included if they were population-based studies, which not only reported the association between particular matter $\left(\mathrm{PM}_{25}\right.$ or $\left.\mathrm{PM}_{10}\right)$ and CIMT, but also provided original data for particular matter $\left(\mathrm{PM}_{2.5}\right.$ or $\left.\mathrm{PM}_{10}\right)$ and carotid artery intima-media thickness. There were no language restrictions. We excluded duplicates, summaries, reviews, letters, commentaries and editorials, toxicological studies, case reports and case series. In this way we selected 13 studies meeting the inclusion criteria. However, 2 of these studies, which only presented the median value or the percentage change of CIMT, didn't have adequate data for CIMT. We contacted authors for detail data and no answer was obtained, so the 2 studies were excluded and 11 studies were finally included in our metaanalyses (Figure 1).

\section{Study selection}

By screening all titles and abstracts potentially eligible studies were selected by two independent investigators (X.L. and H.L.). Then the eligibility of the study for the meta-analysis was picked out by reading the full text of the potentially eligible studies. If the two reviewers had disagreements, a third reviewer (R.L.) would help adjudicate conflicts.

\section{Data extraction}

On the basis of in-depth reading of all eligible literatures we extracted the useful data and enter it in an in advance designed standardized information table, which presented a comprehensive description of the study characteristics, including title, first author, journal publication year, study design, location and period, characteristics of the participants (age, sex, physical condition, sample size), measurement of CIMT, data analysis model, exposure measurement, effect measurement and confounding factors adjusted (age, sex, race, education, temperature, humidity and so on). Two reviewers (X.L. and H.L.) completed the operation of data extraction respectively and then compared. In case of conflict, a third reviewers (R.L.) was asked to judge and make a decision.

\section{Statistical analysis}

We transformed the value of CIMT with 95\% CIs from each study for a standardized increment per $10 \mu \mathrm{g} / \mathrm{m}^{3}$ in particular matter $\left(\mathrm{PM}_{25}\right.$ $\left.\mathrm{PM}_{10}\right)$ and took it as our outcome. In addition, we hypothesized a linear relation between exposure and outcome because most studies used linear regression models. On account of different study design, geographical settings, methods of exposure and CIMT measurement, characteristics of participants and exposure duration, heterogeneity existed in the studies. Therefore, we used the random-effects model, which accounts for both within and between studies heterogeneity to pool the summary-effect estimates. According to the weight $\left(1 / \mathrm{SE}^{2}\right)$ of each study account for the total, we calculated the overall effect. Standard $\mathrm{I}^{2}$ statistic was applied to tests for heterogeneity in order

*Corresponding author: Zhongjie Fan, Department of Cardiology, Peking Union Medical College Hospital, Peking Union Medical College and Chinese Academy of Medical Sciences, PR China, Tel: 86-10-6915-5066; E-mail: Fan@pumch.cn

Received August 13, 2015; Accepted August 26, 2015; Published August 31, 2015

Citation: Liu X, Lian H, Ruan Y, Liang R, Zhao X, et al. (2015) Association of Exposure to Particular Matter and Carotid Intima-Media Thickness: A Systematic Review and Meta-Analysis. J Environ Anal Chem 2: 156. doi: 10.4172/2380-2391.1000156

Copyright: () 2015 Liu X, et al. This is an open-access article distributed under the terms of the Creative Commons Attribution License, which permits unrestricted use, distribution, and reproduction in any medium, provided the original author and source are credited. 
to quantify inconsistencies between studies. $\mathrm{I}^{2}$ values of $25 \%$ or less, $50 \%$ and $75 \%$ or more stand for low, moderate and high heterogeneity respectively.

We also did subgroup analyses stratifying studies performed by study design (cross-sectional VS longitudinal), sex (female vs male), education (low education vs high education), treatment (lipid-lowing treatment vs no lipid-lowing treatment). In addition, association between traffic proximity and CIMT was also assessed. To estimate the potential publication bias, funnel plots were constructed and we also tested them using the Egger regression test due to the limitations of funnel plot. Statistical analyses were conducted using Stata software (Stata Corp., College Station, Texas, USA). Statistical significance was taken as two-sided $P<0.05$ with the exception of the heterogeneity assessment, which was considered statistically significant at $P<0.10$.

\section{Results}

\section{Literature search}

104 initial records were retrieved by searching databases and 56 remained after removing duplicates. Then by screening the titles and abstracts, 35 articles were excluded, which were animal studies or not primary documents (review, letter). After that we read the full text of the remaining 21 studies and determined 13 of them were fulfilled the eligibility criteria. Whereas 2 studies did not present sufficient data for mean value of CIMT and authors did not respond to our e-mails $[14,15], 11$ articles were finally eligibility of the review and metaanalysis (Figure 1).

\section{Study characteristics}

The characteristics of included studies are presented in the Table 1. Among the eligible studies, nine used cross-sectional design, one used longitudinal design, and another one used both study designs. Study locations were mainly (6 studies) USA, except that two studies (one of them including 4 cohorts) were Europe, one study was Canada and one was Taiwan. The sample size of participants ranged from 509 to 6256 . The population of these studies was all adults and most of them were healthy. 4 studies selected the population from a same existing cohort, participant $s$ of which aged from 45 to 84 and without preexisting

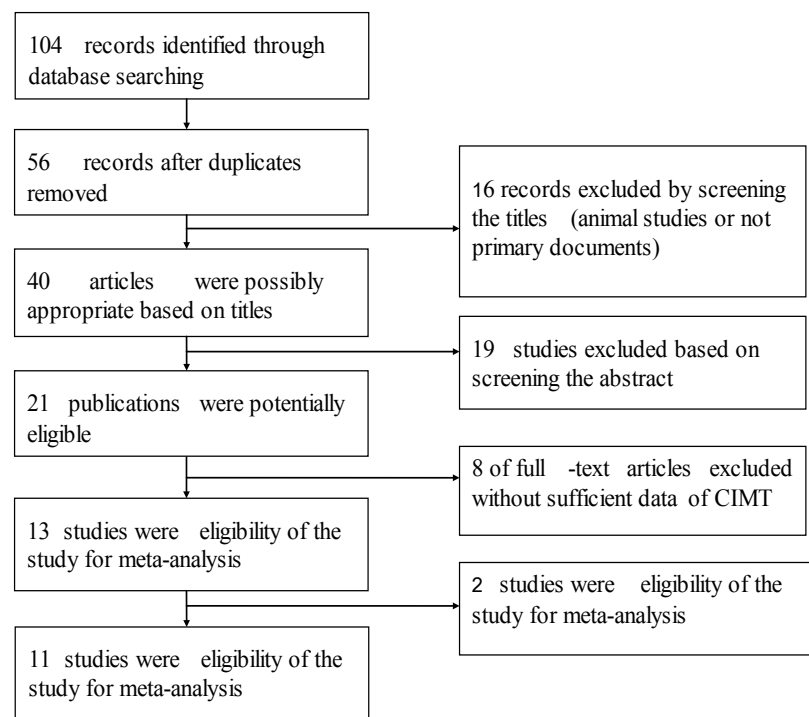

Figure 1: Flow chart of studies selection in the meta-analysis. clinically apparent cardiovascular disease. In addition, one study was conducted in young adults aged from 18 to 27 .

Particular matter in 10 studies is $\mathrm{PM}_{2.5}, 1$ study was $\mathrm{PM}_{10}$ and 3 studies were both. The concentrations of $\mathrm{PM}_{10}$ and $\mathrm{PM}_{2.5}$ were estimated in ambient or individual-level. Linear regression model was used to evaluate the association between air pollution and CIMT in most studied. The number of potential confounding factors included in the studies varied, most adjusted for age, sex, race/ethnicity, BMI, smoking status, education, and LDL-C in the results.

\section{Analysis}

The results from the random-effects meta-analysis of the relationship between exposure to $\mathrm{PM}_{25}$ and CIMT are shown in Figure 2. When the concentration of $\mathrm{PM}_{2.5}$ increased $10 \mu \mathrm{g} / \mathrm{m}^{3}$ in the evaluation of overall combination, its relationship with CIMT reached statistical significance (the increment of CIMT is $16.79 \mu \mathrm{m}$; $95 \% \mathrm{CI}$, 4.95-28.63 $\mu \mathrm{m}$ ). The heterogeneity observed for 10 studies was small medium $\left(I^{2}=67.6 \%\right)$. When some of the eligible studies were pooled with an additional adjustment for education and income, the summary estimate was attenuated to $16.68 \mu \mathrm{m}(95 \% \mathrm{CI}, 4.93-28.43 \mu \mathrm{m})$, results were not shown in the table.

There was no statistical evidence of publication bias in overall analyses. In Egger's test we got $P=0.211$. The subgroup analysis about $\mathrm{PM}_{2.5}$ and CIMT was conducted by sex education lipid-lowing treatment and study design. Significant association between $\mathrm{PM}_{25}$ and CIMT was found with female, the summary estimate of which was larger than overall analysis $(64.42 \mu \mathrm{m}$; $95 \% \mathrm{CI}, 38.44-90.39$ $\mu \mathrm{m})$. However, the association with male had no statistic significant. Similarly, in longitudinal study design a weak correlation between exposure to $\mathrm{PM}_{25}$ and CIMT was represented (5.50 $\mu \mathrm{m}$; 95\% CI, 0.00$10.99 \mu \mathrm{m})$, comparing with no significant association in cross-sectional study design $(22.60 \mu \mathrm{m} ; 95 \% \mathrm{CI},-8.39-53.60 \mu \mathrm{m})$. The subgroup analysis stratified by educational qualifications showed that people with low education had a larger effect than high education, whereas neither of them had statistic significant [16]. The pooled estimates of low education and high education were $31.80 \mu \mathrm{m}$ (95\% CI, -4.16$67.77 \mu \mathrm{m})$ and $14.46 \mu \mathrm{m}(95 \% \mathrm{CI},-15.47-44.40 \mu \mathrm{m})$, respectively. When compared the effects based on whether receive the lipid-lowing treatment, we also found a difference. Participants with a lipid-lowing treatment showed an increase of CIMT with $43.57 \mu \mathrm{m}$ (95\% CI, -12.12$99.27 \mu \mathrm{m}$ ), whereas people had no lipid-lowing treatment was $24.74 \mu \mathrm{m}$ (95\% CI, -7.75-57.25 $\mu \mathrm{m}$ ) (Figure 3).

Squares represent study-specific estimates (size of the square reflects the study-specific statistical weight); horizontal lines represent 95\% confidence intervals (CIs); diamonds represent the total effect with corresponding 95\% confidence interval (CIs). IMPROVE-Stockholm, HNR, KORA and REGICOR are four on-going European cohort analyzed by Perez et al. [17].

Summary estimate for $\mathrm{PM}_{10}$ is shown in Figure 4. When the concentration of $\mathrm{PM}_{10}$ increased $10 \mu \mathrm{g} / \mathrm{m}^{3}$ in the evaluation of overall combination, the CIMT increment is $4.13 \mu \mathrm{m}$; (95\% CL, -5.79-14.04 $\mu \mathrm{m})$, which was inverse in comparison with $\mathrm{PM}_{2.5}$ but not statistically significant, though there was significant heterogeneity across the studies $\left(\mathrm{I}^{2}=66.5 \%\right.$ or $\left.\mathrm{p}=0.006\right)$ in associations with $\mathrm{PM}_{10}$.

We also estimated the relationship between CIMT and traffic proximity [18-26]. For people living near the traffic inconsistencies were existent within and between different studies on the association between traffic proximity and the variation of CIMT compared with participants living away from major roadways. 
Citation: Liu X, Lian H, Ruan Y, Liang R, Zhao X, et al. (2015) Association of Exposure to Particular Matter and Carotid Intima-Media Thickness: A Systematic Review and Meta-Analysis. J Environ Anal Chem 2: 156. doi:10.4172/2380-2391.1000156

Page 3 of 7

\begin{tabular}{|c|c|c|c|c|c|c|c|}
\hline Author [Ref. No.] & Location & Period & Study design & Sample size & Age (years) & $\begin{array}{c}\text { Exposure } \\
\text { measurement }\end{array}$ & Statistical analysis \\
\hline Su et al. [16] & Taiwan & $2009-2011$ & cross-sectional & 689 & $35-65$ & Individual & $\begin{array}{c}\text { multiple linear regression } \\
\text { model }\end{array}$ \\
\hline Perez et al. [17] & Europe & $1997-2009$ & cross-sectional & 9183 & $42-68$ & Individual & linear regression model \\
\hline Kim et al. [18] & USA & $2000-2002$ & cross-sectional & 5488 & $45-84$ & Individual & $\begin{array}{c}\text { multiple linear regression } \\
\text { model }\end{array}$ \\
\hline Gan et al. [19] & Canada & $2004-2011$ & longitudinal & 509 & $30-65$ & Individual & $\begin{array}{c}\text { general linear regression } \\
\text { model }\end{array}$ \\
\hline Sun et al. [20] & USA & $2000-2002$ & cross-sectional & 6256 & $45-84$ & Ambient & $\begin{array}{c}\text { multiple linear regression } \\
\text { model }\end{array}$ \\
\hline Adar et al. [21] & USA & $2000-2005$ & cross-sectional & 5660 & $45-84$ & Individual & longitudinal mixed model \\
\hline Breton et al. [22] & USA & $2007-2009$ & cross-sectional & 768 & $18-27$ & Ambient & linear regression model \\
\hline Tonne et al. [23] & Britain & $2002-2006$ & cross-sectional & 2348 & $55-67$ & Individual & $\begin{array}{l}\text { generalized linear regression } \\
\text { models }\end{array}$ \\
\hline Künali et al. [24] & USA & $1994-2006$ & cross-sectional, longitudinal & 1483 & $>30$ & Ambient & linear regression model \\
\hline Lenters et al. [25] & Netherlands & $1999-2000$ & cross-sectional & 745 & $45-84$ & Individual & $\begin{array}{c}\text { multiple linear regression } \\
\text { model }\end{array}$ \\
\hline Künali et al. [26] & USA & $1998-2003$ & cross-sectional & 798 & $>40$ & Ambient & linear regression model \\
\hline
\end{tabular}

Table 1: Characteristics of studies that were eligible for this review and meta-analysis of associations between particular matter $\left(\mathrm{PM}_{2.5}\right.$, $\left.\mathrm{PM}_{10}\right)$ and carotid intima-media thickness.

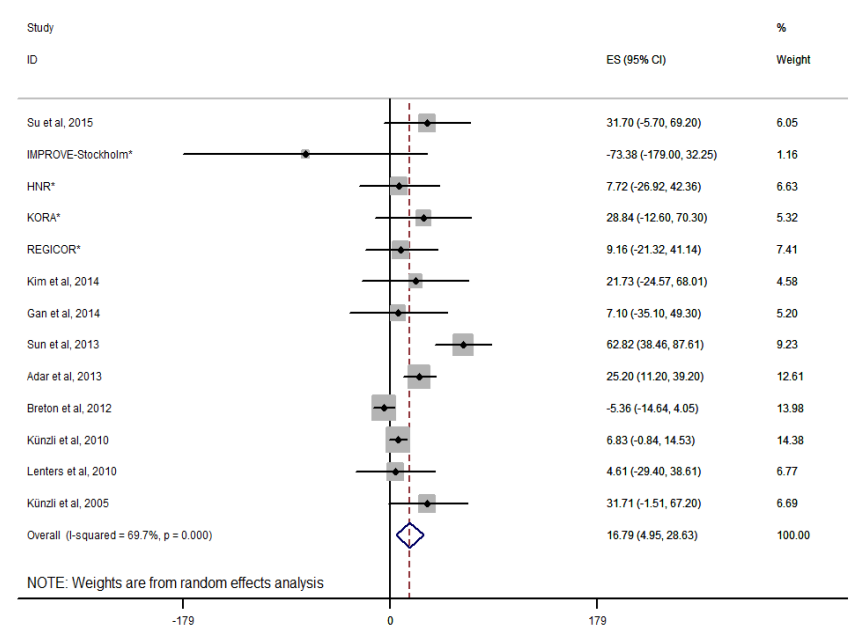

Figure 2: Forest plot for overall analysis of the association between $\mathrm{PM}_{25}$ and carotid intima-media thickness (random-effects model).

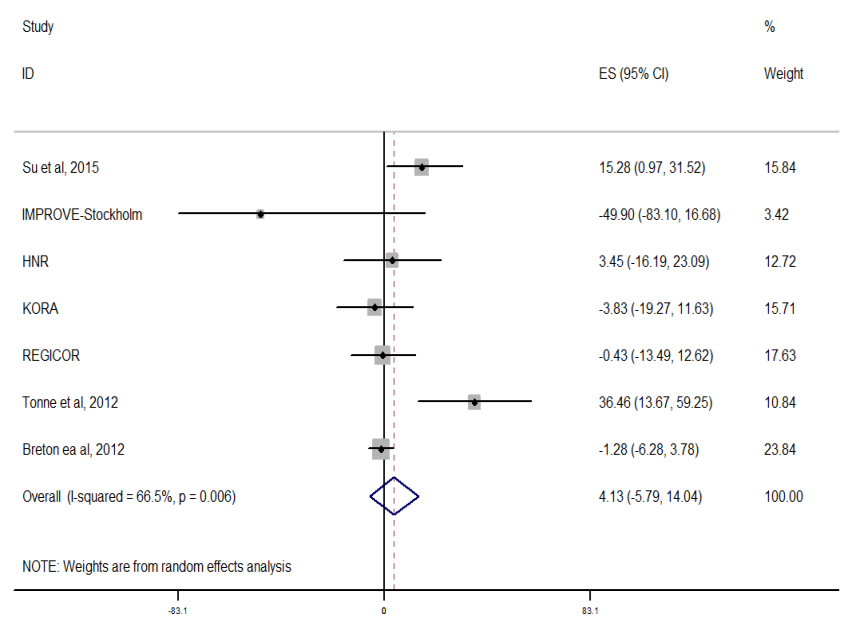

Figure 3: Subgroup analyses based on sex, education, treatment and study design. Square represent each subgroup estimate (size of the square reflects the statistical weight); horizontal lines represent $95 \%$ confidence intervals (Cls).

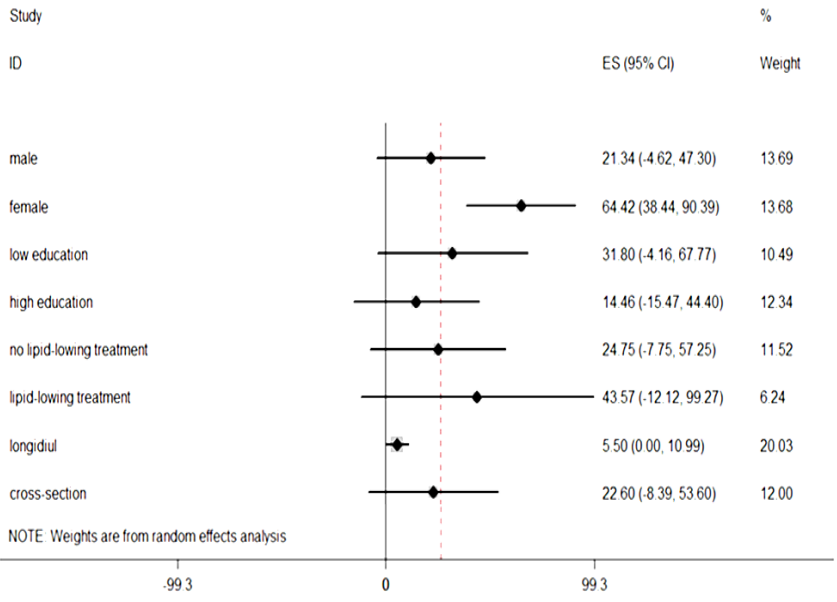

Figure 4: Forest plot for overall analysis of the association between $\mathrm{PM}_{10}$ and carotid intima-media thickness (random-effects model).

\section{Discussion}

This study is the first meta-analysis to our knowledge to estimate the effects of exposure to particular matter $\left(\mathrm{PM}_{2.5}, \mathrm{PM}_{10}\right)$ on CIMT, an accepted measure of the progression of atherosclerosis [27,28]. In overall estimation we observed a significant and positive association between $\mathrm{PM}_{2.5}$ and CIMT. When compared with the overall analysis, subgroup analyses were associated with lower heterogeneity and had the same direction of estimated effect. Therefore, the association was robust.

Two studies we excluded due to no sufficient data for mean value of CIMT showed similar results. One is in Germany [14] Median CIMT of the 3,380 analyzed participants was $0.66 \mathrm{~mm}$ (interquartile range 0.16 $\mathrm{mm})$. An interdecile range increase in $\mathrm{PM}(2.5)\left(4.2 \mu \mathrm{g} / \mathrm{m}^{3}\right), \operatorname{PM}(10)$ $\left(6.7 \mu \mathrm{g} / \mathrm{m}^{3}\right)$, and distance to high traffic $(1,939 \mathrm{~m})$ was associated with a $4.3 \%$ (95\% confidence interval [CI]: $1.9 \%$ to $6.7 \%), 1.7 \%$ (95\% CI: $-0.7 \%$ to $4.1 \%$ ), and $1.2 \%$ (95\% CI: $-0.2 \%$ to $2.6 \%$ ) increase in CIMT, respectively; The other one is in the USA [15]: Intimal-medial thickness was weakly, positively associated with exposures to particulate matter $<10$ micron in aerodynamic diameter and $<2.5$ micron in aerodynamic diameter after controlling for age, sex, race/ethnicity, socioeconomic 
factors, diet, smoking, physical activity, blood lipids, diabetes, hypertension, and body mass index (1-4\% increase per 21 microgram/ $\mathrm{m}^{3}$ increase in particulate matter $<10$ micron in aerodynamic diameter or a 12.5 microgram $/ \mathrm{m}^{3}$ increase in particulate matter $<2.5$ micron in aerodynamic diameter). Results were consistent from a qualitative angle and did not affect the meta analysis results in our paper.

CIMT results from the processes of cumulative atherogenesis and is a predictor of cardiovascular events. In comparison with pulse wave velocity and augmentation index, which are affected by changes in blood pressure, CIMT is quite easy to be measured due to little shortterm variation, therefore, many previous environment studies applied it to measure the degree of atherosclerosis [29-32]. Inflammatory dysfunction [33], the excitation of oxidative stress and autonomic imbalance are thought to be the potential pathways, by which particular matter is associated with atherogenesis. Then these potential pathways lead to endothelial dysfunction and reduction of vascular reactivity, which have been proved to be early manifestations of atherosclerosis by many studies [34]. Hoffmann et al. [35] paper from the Heinz Nixdorf Study showed fine particulate matter exposure was associated with coronary artery calcification (CAC), which is related in relevant ways to CIMT. Wilker et al. [36] reported annual mean black carbon concentration was associated with CIMT in a population of elderly men. These findings support an association between long-term air pollution exposure and atherosclerosis. Many animal experiments also support the viewpoint that exposure to $\mathrm{PM}_{2.5}$ may contribute to the process of atherosclerosis by potential mechanisms including bone marrow stimulation, release of monocytes and altered vasomotor tone [37-39]. Apolipoprotein E-/- mice expose to $\mathrm{PM}_{2.5}$ had an effect on altered vasomotor tone, vascular inflammation and increase of aortic atherosclerosis [37]. In addition, animal experiments found other biologic mechanisms, which connect particulate matter exposure with the progress of atherosclerosis in a long-term period, were that exposure to particular matter may influence blood pressure, autonomic function and low density lipoprotein oxidation [40-44].

As shown in Figure 3, we found the size of the effect was larger in women. The result may suggest that sex can influence the association between $\mathrm{PM}_{2.5}$ and CIMT. We hypothesize that one potential mechanism is based on the secretion of androgen. If male expose to cardiovascular risk factors such as particular matter dominate atherosclerosis, a smaller effect signal would be shown in the estimates among men. In addition, compared with young men, elderly men with less androgen have higher risk for atherosclerosis [26]. The other potential pathway is that females have slightly greater airway reactivity than males. Thus, compared with males we might find dose-response relations more easily in females [45]. Although some previous studies have also reported that particular matter had greater effect estimates in women than in men $[45,46]$, the effect modification by sex remains unclear and further investigations are needed [47]. Our findings showed that the associations were slightly stronger when analyses were limited to studies with participants receiving higher education. As a measure of socioeconomic status (SES), individual education attainment may impact the health effects of particular matter in several pathways. Firstly, because of poor living conditions or occupation people with lower education are more likely to live near busy roads and expose to multiple air pollutants. Many previous studies have proved this phenomenon. For example, higher concentrations of some air pollution have been demonstrated among disadvantaged groups [48]. Studies for Scandinavian indicated the discrepancy of personal exposures to particular matter among people with different education and occupation $[49,50]$. Secondly, a majority of people receiving lower education have poor living conditions and don't have ability to get enough nutrition, such as antioxidant polyunsaturated fatty acids and vitamins, which may protect against adverse effects of particular matter [51]. Thirdly, people with lower SES have a higher prevalence of preexisting diseases and usually receive inferior medical treatment for them, which leads to higher sensitivity of air pollution-related health hazards. Existing evidence have shown that lipid-lowing treatment may affect the association between $\mathrm{PM}_{2.5}$ and CIMT. Some studies reported, that participants taking lipid-lowing medications at baseline represented stronger association between CIMT and $\mathrm{PM}_{2.5}[24,26]$. These results also agree with hyperlipidemic rabbits experiments estimating effects of PM on atherosclerosis [38,52]. In these rabbits relationship between the amount of PM contained in the alveolar macrophages and atherogenic reaction was found. However, the modification direction reported in other study was inconsistent, so the summary estimate of people with lipid-lowing treatment in our study was not significant and only slightly different from those without treatment. In order to illuminate the relevance of lipid and statin status, future researches can be conducted among cohorts with familial hypercholesteremia $[53,54]$. We also demonstrated longitudinal results have stronger association in contrast to cross-sectional study design. Moreover, when excluding cross-sectional studies, the relevance between $\mathrm{PM}_{2}$ and CIMT had no statistical significance. Because in cross-sectional studies we measured CIMT at a single point in time per participant and associations are based on between-person contrasts, these effects may be more affected without controlling for person-level factors and intra-individual variability of CIMT than those in longitudinal studies, in which information derived from the same individual.

Living close to major roads may indicate high exposure to trafficrelated exhaust emissions, such as ultrafine particles and other highly redox-active pollution especially diesel particles [55]. Nonetheless, the relation between CIMT or other atherosclerosis markers and traffic proximity were still unclear, as the findings of existing studies were inconsistent. In our meta-analysis 4 studies observed the relation between traffic and CIMT. Perez et al. [17] presented that living in proximity to high traffic was also positively but not significantly associated with CIMT. Künzli et al. [24] showed that with a $10 \mu \mathrm{g} / \mathrm{m}^{3}$ increasing in $\mathrm{PM}_{25}$ annual increase in CIMT was $2.5 \mu \mathrm{m}$ (95\% CI -0.3$5.4 \mu \mathrm{m}$ ), which had no significant. When living within $100 \mathrm{~m}$ traffic, annual CIMT increased $5.5 \mu \mathrm{m}$ (95\% CI 0.13-10.79 $\mu \mathrm{m})$ compared with people living away from traffic. However, living within a highway (100 $\mathrm{m})$ or within a major road $(50 \mathrm{~m})$ was related with a non-significant $1.6 \mu \mathrm{m}(95 \% \mathrm{CI}-0.15-3.42 \mu \mathrm{m})$ augment in CIMT per year. Lenters et al. [25] didn't find consistent direction of association between traffic indicators (traffic proximity, traffic density) and CIMT. Similarly results were also represented by Gan et al. [19]. Several other recent studies observing the associations of CIMT with biomass fuel [56] and traffic-related air pollution $[57,58]$ showed statistic significant results. Rivera et al. [52] reported that exposure contrasts between the 5th and 95th percentiles for $\mathrm{NO}_{2}\left(25 \mu \mathrm{g} / \mathrm{m}^{3}\right)$, traffic intensity in the nearest street (15,000 vehicles/day), and traffic load within $100 \mathrm{~m}(7,200,000$ vehicle-m/day) were related with $0.56 \%$ (95\% CI: $-1.5,2.6 \%), 2.32 \%$ (95\% CI: $0.48,4.17 \%)$, and $1.91 \%$ (95\% CI: $-0.24,4.06)$ percent difference in IMT, respectively. Whereas other scholars examined the association of long-term exposure to traffic with CIMT in children [58]. The results showed that children residing $<100$ meters from the nearest heavily trafficked road had mean and maximum CIMT increment of $15 \%$ and $11 \%$ compared to those living $\geq 200$ meters away $(P=0.0001)$. From the above, future researches should focus on the effects of traffic proximity on atherosclerosis. Furthermore, studies can also be conducted to find if CIMT is a necessary ideal marker to reflect adverse 
effects of atherosclerosis related with particular matter.

The results for $\mathrm{PM}_{10}$ presented by Perez et al. [17] were fairly inconsistent with those from a study based on 2348 participants of the Whitehall II cohort of British civil servants and from a past HNR study (Bauer et al. [33]; Tonne et al. [23]). Whitehall II reported a 5\% change (95\% CI, 1.9\%, 8.3\%) for an IQR increase of $5.2 \mu \mathrm{g} / \mathrm{m}^{3} \mathrm{PM}_{10} . \mathrm{HNR}$ showed a positive but not statistically significant association with $\mathrm{PM}_{10}$ ( $1.8 \%$ change [ $95 \% \mathrm{CI}, 0.6 \%, 4.3 \%]$ per $6.7 \mu \mathrm{g} / \mathrm{m}^{3}$ increase of $\mathrm{PM}_{10}$ ).

Several potential limitations should be noted in our study. Firstly, heterogeneity due to distinction between individuals and between studies was found across all researches, such as publication year, location, study design, study period, characteristics of participants, $\mathrm{PM}_{25}$ and $\mathrm{PM}_{10}$ measurement, sample size, covariates in each study and measuring method of CIMT. According to existing detailed protocols about measurement technique and analysis, the CIMT was assessed noninvasively by B-mode ultrasound imaging coupled with automatic data processing systems. However, the optimal site and used value are still uncertain [30]. Some studies utilized the value of mean CIMT of the right far common carotid wall. Other studies regarded the average of the largest IMT in the left and right carotid arteries as a person's CIMT. Still one study used mean of all available maximum wall thicknesses. In addition, choosing to use the cross-sectional CIMT or progression of CIMT also make some differences. Thus heterogeneity exists in the measurement of CIMT. Health status of participants and medication use were other potential factors having effects on outcome. Different statistical methods conclude linear regression model and longitudinal mixed model as well as the varying adjusted factors used in different studies may also product heterogeneity. Besides the heterogeneity factors we referred above, the limited number of the included studies and inferences in our meta-analysis make it difficult for us to find other potential factors by further analysis. As a result of which, heterogeneity, publication bias and quality reduction for studies arose. Secondly, since few involved studies used "multipollution" model, we only put "single-pollution" model into use in our study regardless of latent interactions between pollutants. Therefore, we can't estimate the interaction of multipollution associated with CIMT. Thirdly, some potential confounding factors were shown by subgroup analysis and additional overall analysis, which assessed the pooled-effect after putting an additional adjustment for education and income in some included studies. Nonetheless, more confounding factors are not able to be represented by more stratified analysis due to the less number of studies and limited information they provide.

The major strength of our study is the comprehensive retrieval in multiple databases and without publication language limitation. Moreover, the studies involved in our meta-analysis most had a large, well-examined population-based sample, which derived from an existing cohort.

Our study provides further evidence that particular matter exposure may increases the risks of arteriosclerosis as well as the morbidity and mortality of cardiovascular diseases. Almost all of studies included in our meta-analysis used linear regression model to estimate the relationship between particular matter $\left(\mathrm{PM}_{2.5}, \mathrm{PM}_{10}\right)$ and CIMT. If the association is linear, it is of great value to reduce the concentration of $\mathrm{PM}_{25}$ at all levels and can provide a basis for the government to issue regulations about decrease of particular matter emission. In view of the limited number of existing studies about association between particular matter and CIMT, more analogous studies should be conducted in the future to further verify the results. In addition, future research can also focus on distinguishing potential confounding factors that impact the effect of $\mathrm{PM}_{2.5}$ and $\mathrm{PM}_{10}$ on CIMT, such as noise, postmenopausal women, diabetics or physical exercises.

In conclusion, our results represented that an increase in $\mathrm{PM}_{25}$ had a significant association with CIMT, which is a mark for subclinical atherosclerosis. In female the effect may be more obvious and statistic significant, while the relationship of the effect with education level and lipid-lowing treatment status was still unclear.

\section{Methods}

Pubmed, Ovid Medline, Embase and NICK between 1948 and 31 March 2015 were searched by combining the keywords about exposure (air pollution, air pollutants, particular matter, $\mathrm{PM}_{2.5}$ and $\mathrm{PM}_{10}$ ) to the outcome related words (carotid intima-media thickness, Carotid atherosclerosis, carotid IMT, CIMT, subclinical atherosclerosis). Two independent researchers selected the eligible studies successively by screening titles, abstracts and by reviewing the full text of potentially qualified studies. Then descriptive and quantitative information was extracted from each included study. The random-effects model was applied in computing the change of carotid intima-media thickness (CIMT) and their corresponding 95\% confidence interval (95\% CI) The effect of potential confounding factors was assessed by stratified analysis and the impact of traffic proximity was also estimated.

\section{Results}

Findings of 56 identified studies, 11 articles satisfied the inclusion criteria. In overall analysis per increment of $10 \mu \mathrm{g} / \mathrm{m}^{3}$ in $\mathrm{PM}_{25}$ was positively associated with an augment of CIMT $(16.79 \mu \mathrm{m} ; 95 \% \mathrm{CI}$, 4.95-28.63 $\mu \mathrm{m})$. When the concentration of $\mathrm{PM}_{10}$ increased $10 \mu \mathrm{g} / \mathrm{m}^{3}$ in the evaluation of overall combination, the CIMT increment is 4.13 $\mu \mathrm{m}(95 \% \mathrm{CI},-5.79-14.04 \mu \mathrm{m})$. Results shown in subgroup analysis had reference value for comparing with those of the overall analysis. The impact of traffic proximity on CIMT was uncertain.

\section{Conclusion}

Exposure to $\mathrm{PM}_{2.5}$ had a significant association with CIMT and for women the effect may be more obvious.

\section{References}

1. Miller KA, Siscovick DS, Sheppard L, Shepherd K, Sullivan JH, et al. (2007) Long-term exposure to air pollution and incidence of cardiovascular events in women. N Engl J Med 356: 447-458.

2. Pope CR, Burnett RT, Thurston GD, Thun MJ, Calle EE, et al. (2004) Cardiovascular mortality and long-term exposure to particulate air pollution: epidemiological evidence of general pathophysiological pathways of disease. Circulation 109: 71-77.

3. Hoek G, Brunekreef B, Goldbohm S, Fischer P, van den Brandt PA (2002) Association between mortality and indicators of traffic-related air pollution in the Netherlands: a cohort study. Lancet 360: 1203-1209.

4. Dockery DW, Pope CA 3rd, Xu X, Spengler JD, Ware JH, et al. (1993) An association between air pollution and mortality in six U.S. cities. N Engl J Med 329: $1753-1759$.

5. Liang R, Zhang B, Zhao X, Ruan Y, Lian H, et al. (2014) Effect of exposure to PM2.5 on blood pressure: a systematic review and meta-analysis. J Hypertens 32: $2130-2140$.

6. Zhao X, Sun Z, Ruan Y, Yan J, Mukherjee B, et al. (2014) Personal black carbon exposure influences ambulatory blood pressure: air pollution and cardiometabolic disease (AIRCMD-China) study. Hypertension 63: 871-877.

7. Brook RD, Rajagopalan S, Pope CA 3rd, Brook JR, Bhatnagar A, et al. (2010) Particulate matter air pollution and cardiovascular disease: An update to the scientific statement from the American Heart Association. Circulation 121: 2331-2378. 
Citation: Liu X, Lian H, Ruan Y, Liang R, Zhao X, et al. (2015) Association of Exposure to Particular Matter and Carotid Intima-Media Thickness: A Systematic Review and Meta-Analysis. J Environ Anal Chem 2: 156. doi:10.4172/2380-2391.1000156

8. Libby P, Theroux P (2005) Pathophysiology of coronary artery disease. Circulation 111: 3481-3488

9. Lusis AJ (2000) Atherosclerosis. Nature 407: 233-241.

10. Ross R (1993) The pathogenesis of atherosclerosis: a perspective for the 1990s. Nature 362: 801-809.

11. Stein JH, Korcarz CE, Hurst RT, Lonn E, Kendall CB, et al. (2008) Use of carotid ultrasound to identify subclinical vascular disease and evaluate cardiovascular disease risk: a consensus statement from the American Society of Echocardiography Carotid Intima-Media Thickness Task Force. Endorsed by the Society for Vascular Medicine. J Am Soc Echocardiogr 21: 93-111.

12. Chambless LE, Folsom AR, Clegg LX, Sharrett AR, Shahar E, et al. (2000) Carotid wall thickness is predictive of incident clinical stroke: the Atherosclerosis Risk in Communities (ARIC) study. Am J Epidemiol 151: 478-487.

13. Chambless LE, Heiss G, Folsom AR, Rosamond W, Szklo M, et al. (1997) Association of coronary heart disease incidence with carotid arterial wal thickness and major risk factors: the Atherosclerosis Risk in Communities (ARIC) Study, 1987-1993. Am J Epidemiol 146: 483-494.

14. Bauer M, Moebus S, Möhlenkamp S, Dragano N, Nonnemacher M, et al (2010) Urban particulate matter air pollution is associated with subclinical atherosclerosis: results from the HNR (Heinz Nixdorf Recall) study. J Am Coll Cardiol 56: 1803-1808

15. Diez RA, Auchincloss AH, Franklin TG, Raghunathan T, Barr RG, et al. (2008) Long-term exposure to ambient particulate matter and prevalence of subclinical atherosclerosis in the Multi-Ethnic Study of Atherosclerosis. Am J Epidemio 167: 667-675.

16. Su TC, Hwang JJ, Shen YC, Chan CC (2015) Carotid Intima-Media Thickness and Long-Term Exposure to Traffic-Related Air Pollution in Middle-Aged Residents of Taiwan: A Cross-Sectional Study. Environ Health Perspect 123 773-778.

17. Perez L, Wolf K, Hennig F, Penell J, Basagaña X, et al. (2015) Air pollution and atherosclerosis: a cross-sectional analysis of four European cohort studies in the ESCAPE study. Environ Health Perspect 123: 597-605.

18. Kim SY, Lianne Sheppard, Joel D Kaufman, Silas Bergen, Adam A Szpiro et al. (2014) Individual-level concentrations of fine particulate matter chemica components and subclinical atherosclerosis: a cross-sectional analysis based on 2 advanced exposure prediction models in the multi-ethnic study of atherosclerosis. Am J Epidemiol 180: 718-728.

19. Gan WQ, Allen RW, Brauer M, Davies HW, Mancini GB, et al. (2014) Long term exposure to traffic-related air pollution and progression of carotid artery atherosclerosis: a prospective cohort study. BMJ Open 4: e004743.

20. Sun M, Kaufman Joel D, Kim Sun-Young, Larson Timothy V, Gould Timothy R, Polak Joseph F, et al. (2013) Particulate matter components and subclinical atherosclerosis: Common approaches to estimating exposure in a Multi-Ethnic Study of Atherosclerosis cross-sectional study. Environmental Health: A Global Access Science Source 12-1.

21. Adar SD, Sheppard L, Vedal S, Polak JF, Sampson PD, et al. (2013) Fine Particulate Air Pollution and the Progression of Carotid Intima-Medial Thickness: A Prospective Cohort Study from the Multi-Ethnic Study of Atherosclerosis and Air Pollution. PLoS Medicine 10.

22. Breton CV, Wang X, Mack WJ, Berhane K, Lopez M, et al. (2012) Childhood air pollutant exposure and carotid artery intima-media thickness in young adults. Circulation 126: 1614-1620.

23. Tonne C, Yanosky JD, Beevers S, Wilkinson P, Kelly FJ (2012) PM mass concentration and PM oxidative potential in relation to carotid intima-media thickness. Epidemiology 23: 486-494.

24. Künzli N, Jerrett M, Garcia-Esteban R, Basagaña X, Beckermann B, et al (2010) Ambient air pollution and the progression of atherosclerosis in adults. PLoS One 5: e9096.

25. Lenters V, Uiterwaal CS, Beelen R, Bots ML, Fischer P, et al. (2010) Long-term exposure to air pollution and vascular damage in young adults. Epidemiology 21: $512-520$.

26. Künzli N, Jerrett M, Mack WJ, Beckerman B, LaBree L, et al. (2005) Ambient air pollution and atherosclerosis in Los Angeles. Environ Health Perspect 113 201-206.

27. Hodis HN, Mack WJ, LaBree L, Selzer RH, Liu CR, et al. (1998) The role of carotid arterial intima-media thickness in predicting clinical coronary events. Ann Intern Med 128: 262-269.
28. Blankenhorn DH, Hodis HN (1994) George Lyman Duff Memorial Lecture. Arterial imaging and atherosclerosis reversal. Arterioscler Thromb 14: 177-192.

29. Künzli N, Perez L, von Klot S, Baldassarre D, Bauer M, et al. (2011) Investigating air pollution and atherosclerosis in humans: concepts and outlook. Prog Cardiovasc Dis 53: 334-343.

30. Johnson HM, Douglas PS, Srinivasan SR, Bond MG, Tang R, et al. (2007) Predictors of carotid intima-media thickness progression in young adults: the Bogalusa Heart Study. Stroke 38: 900-905.

31. O'Leary DH, Polak JF, Kronmal RA, Manolio TA, Burke GL, et al. (1999) Carotid-artery intima and media thickness as a risk factor for myocardia infarction and stroke in older adults. Cardiovascular Health Study Collaborative Research Group. N Engl J Med 340: 14-22.

32. Hoffmann B, Moebus S, Dragano N, Stang A, Möhlenkamp S, et al. (2009) Chronic residential exposure to particulate matter air pollution and systemic inflammatory markers. Environ Health Perspect 117: 1302-1308.

33. Bauer M, Moebus S, Möhlenkamp S, Dragano N, Nonnemacher M, et al. (2010) Urban particulate matter air pollution is associated with subclinical atherosclerosis: results from the HNR (Heinz Nixdorf Recall) study. J Am Coll Cardiol 56: 1803-1808

34. Hoffmann B, Moebus S, Möhlenkamp S, Stang A, Lehmann N, et al (2007) Residential exposure to traffic is associated with coronary atherosclerosis. Circulation 116: 489-496

35. Wilker EH, Mittleman MA, Coull BA, Gryparis A, Bots ML, et al. (2013) Long-term exposure to black carbon and carotid intima-media thickness: the normative aging study. Environ Health Perspect 121: 1061-1067.

36. Sun Q, Wang A, Jin X, Natanzon A, Duquaine D, et al. (2005) Long-term air pollution exposure and acceleration of atherosclerosis and vascula inflammation in an animal model. JAMA 294: 3003-3010.

37. Suwa T, Hogg JC, Quinlan KB, Ohgami A, Vincent R, et al. (2002) Particulate air pollution induces progression of atherosclerosis. J Am Coll Cardiol 39: 935 942.

38. Fujii T, Hayashi S, Hogg JC, Mukae H, Suwa T, et al. (2002) Interaction of alveolar macrophages and airway epithelial cells following exposure to particulate matter produces mediators that stimulate the bone marrow. Am J Respir Cell Mol Biol 27: 34-41.

39. Brook RD (2005) You are what you breathe: evidence linking air pollution and blood pressure. Curr Hypertens Rep 7: 427-434.

40. Brook RD, Franklin B, Cascio W, Hong Y, Howard G, et al. (2004) Air pollution and cardiovascular disease: a statement for healthcare professionals from the Expert Panel on Population and Prevention Science of the American Heart Association. Circulation 109: 2655-2671.

41. Sharman JE, Coombes JS, Geraghty DP, Fraser DI (2002) Exposure to automotive pollution increases plasma susceptibility to oxidation. Arch Environ Health 57: 536-540.

42. Donaldson K, Stone V, Seaton A, MacNee W (2001) Ambient particle inhalation and the cardiovascular system: potential mechanisms. Environ Health Perspect 109 Suppl 4: 523-527.

43. Creason J, Neas L, Walsh D, Williams R, Sheldon L, et al. (2001) Particulate matter and heart rate variability among elderly retirees: the Baltimore $1998 \mathrm{PM}$ study. J Expo Anal Environ Epidemiol 11: 116-122.

44. Kan H, London SJ, Chen G, Zhang Y, Song G, et al. (2008) Season, sex age, and education as modifiers of the effects of outdoor air pollution on daily mortality in Shanghai, China: The Public Health and Air Pollution in Asia (PAPA) Study. Environ Health Perspect 116: 1183-1188.

45. Zanobetti A, Schwartz J, Gold D (2000) Are there sensitive subgroups for the effects of airborne particles? Environ Health Perspect 108: 841-845

46. Clougherty JE (2010) A growing role for gender analysis in air pollution epidemiology. Environ Health Perspect 118: 167-176.

47. Sexton K, Gong H Jr, Bailar JC 3rd, Ford JG, Gold DR, et al. (1993) Air pollution health risks: do class and race matter? Toxicol Ind Health 9: 843-878.

48. Rotko T, Kousa A, Alm S, Jantunen M (2001) Exposures to nitrogen dioxide in EXPOLIS-Helsinki: microenvironment, behavioral and sociodemographic factors. J Expo Anal Environ Epidemiol 11: 216-223. 
Citation: Liu X, Lian H, Ruan Y, Liang R, Zhao X, et al. (2015) Association of Exposure to Particular Matter and Carotid Intima-Media Thickness: A Systematic Review and Meta-Analysis. J Environ Anal Chem 2: 156. doi:10.4172/2380-2391.1000156

49. Rotko T, Koistinen K, Hänninen O, Jantunen M (2000) Sociodemographic descriptors of personal exposure to fine particles (PM2.5) in EXPOLIS Helsinki. $\mathrm{J}$ Expo Anal Environ Epidemiol 10: 385-393.

50. Romieu I, Téllez-Rojo MM, Lazo M, Manzano-Patiño A, Cortez-Lugo M, et al. (2005) Omega-3 fatty acid prevents heart rate variability reductions associated with particulate matter. Am J Respir Crit Care Med 172: 1534-1540.

51. Goto Y, Hogg JC, Shih CH, Ishii H, Vincent R, et al. (2004) Exposure to ambient particles accelerates monocyte release from bone marrow in atherosclerotic rabbits. Am J Physiol Lung Cell Mol Physiol 287: L79-85.

52. Wiegman A, Hutten BA, de Groot E, Rodenburg J, Bakker HD, et al. (2004) Efficacy and safety of statin therapy in children with familial hypercholesterolemia: a randomized controlled trial. JAMA 292: 331-337.

53. Wittekoek ME, de Groot E, Prins MH, Trip MD, Büller HR, et al. (1999) Differences in intima-media thickness in the carotid and femoral arteries in familial hypercholesterolemic heterozygotes with and without clinical manifestations of cardiovascular disease. Atherosclerosis 146: 271-279.
54. Zhu Y, Hinds WC, Kim S, Sioutas C (2002) Concentration and size distribution of ultrafine particles near a major highway. J Air Waste Manag Assoc 52: 10321042

55. Painschab MS, Davila-Roman VG, Gilman RH, Vasquez-Villar AD, Pollard SL, et al. (2013) Chronic exposure to biomass fuel is associated with increased carotid artery intima-media thickness and a higher prevalence of atherosclerotic plaque. Heart 99: 984-991.

56. Rivera M, Basagaña X, Aguilera I, Foraster M, Agis D, et al. (2013) Association between long-term exposure to traffic-related air pollution and subclinical atherosclerosis: the REGICOR study. Environ Health Perspect 121: 223-230.

57. Sun M, Kaufman JD, Kim SY, Larson TV, Gould TR, et al. (2013) Particulate matter components and subclinical atherosclerosis: common approaches to estimating exposure in a Multi-Ethnic Study of Atherosclerosis cross-sectional study. Environ Health 12: 39

58. Armijos RX, Weigel MM, Myers OB, Li WW, Racines M, et al. (2015) Residentia exposure to urban traffic is associated with increased carotid intima-media thickness in children. J Environ Public Health 2015: 713540. 